\section{State of the Ice in the Arctic Seas}

ThE Danish Meteorological Institute has resumed the publication of its yearly "The State of the Ice in the Arctic Seas", and the issues for 1947 and 1948 have now appeared in the long-familiar style in English (pp. 10+5 maps, 1947 ; pp. 14+5 maps, 1948 ; Copenhagen : G. E. C. Gad, 1950). Data are being collected for 1940-45, and it is hoped to publish soon the reports for these years. The year 1947 seems to have been abnormal in several aspects. The ice in the White Sea and more markedly in the Barents Sea had a greater extent than usual. There is a lack of information from Svalbard; but the east coasts were blocked for part of June and in July. More remarkable was the lack of the heavy pack on the east coast of Greenland in the Greenland Current and in Denmark Strait. No ice was reported on the coasts of Iceland. The ice in the south-west of Greenland was exceptionally light. In 1948, data from Svalbard were scanty; but the ice seems to have been more plentiful than usual. June saw a belt of ice on the west coast, from South Cape to Ice Fjord. Data are wanted from the Barents Sea, but, as usual, Franz Josef Land was unapproachable throughout the summer. Most remarkable was the storis which came round Cape Farewell into Davis Strait, both late and in small quantities. On the Grand Banks the total amount of field ice was less than usual.

\section{Qualitative Control of Seeds in Great Britain}

THE committee appointed by the Ministry of Agriculture to consider the possibility of introducing practical methods of qualitative control of seeds used in the United Kingdom has now issued its report (pp. 32 ; London : H.M. Stationery Office, 1950; 1s.). The current Seeds Act and Seeds Regulations naturally form the basis of the discussion, though the aspects considered cover a somewhat wider field, falling into five main groups: list of seeds to be subject to qualitative control; analytical standards in relation to seed-control measures; incidence of disease ; encouragement of the use of varieties or strains of proved value; and authenticity and purity of strain and variety. A considerable extension in the list of seeds to be included under the Seeds Regulations is suggested, together with a revision of the limits at and below which the percentages of their purity and germination should be declared. Prohibitive minimal percentages of both factors, below which seeds should not be sold for sowing, are also proposed. The current schedule of injurious weeds is enlarged, and a table showing the potential danger of the inclusion of a small proportion of various weed seeds clearly illustrates the necessity for adequate legislative measures on this matter. Recommendations with regard to seed-borne diseases are the outcome of consultations with an ad hoc committee of plant pathologists. The need for the closest co-operation between the seed-testing stations and the plant pathology services is stressed, a first requisite being the development of standard techniques suitable for the detection of potential parasites in seed samples. Since the use of good-quality varieties or strains is fundamental to maximum crop production, the setting-up of a technical committee to advise on this matter is recommended. A list of functions for such a committee is appended, specialist sub-committees being suggested for the consideration of certain aspects, for example, varietal synonyms, seed-borne diseases and seed-testing technique.

\section{Canadian Course on University Lecturing}

THe National Conference of Canadian Universities has decided to repeat this summer the three-week lecture-giving course for university teachers which was held last June (Hon. Sec., T. H. Matthews, McGill University, Montreal, 2). The programme of this school was essentially practical and was intended to help the teacher in the classroom or laboratory. There were a few short provocative talks by the staff upon topics such as the control of the voice, preparing notes for lectures, student notes, the use of a textbook, setting and marking examination papers, and so on, but most of the talking was done by the 'students', who ranged in rank from a full professor to a junior lecturer. Every student gave at least four talks to the others, who acted as the audience. Some of the talks were introductory lectures in courses the speakers were actually giving in their own universities, others were aimed at outside audiences and included adult-education lectures, radio talks and even a speech to a university senate. The talks were all recorded upon tape machines so that speakers might afterwards hear how they sounded to others and could discuss their performances with the staff and with fellow students. In addition, each student was criticized by his audience immediately after his or her speech, and there was a cheerful atmosphere of give-and-take in these discussions. It was surprising to see how quickly some obviously bad lecturing habits disappeared and how the quality of presentation improved under friendly discussion. Every day there were also special round-table discussions which the students themselves ran and which had some very lively arguments.

\section{Cecil Peace Prize}

The Cecil Peace Prize for 1950 has been awarded to Mr. Conrad Ascher, of University College, London, the subject of the essay being "What is meant by the Balance of Power? And has its attempted maintenance since 1660 been useful for Peace or not?" The Prize, which was founded by Viscount Cecil of Chelwood in 1925, is an annual award, worth $£ 100$, and is open to all members (less than twenty-five years old) of the universities of the United Kingdom. The subject for 1951 is "The action of the United Nations to put down aggression ... against the Republic of Korea ... marked a turning point in history" (Mr. Dean Acheson at Flushing Meadow, September 20, 1950). Essays must be sent in before November 1 to the secretary of the Association of Universities of the British Commonwealth, 5 Gordon Square, London, W.C.1, from whom further conditions relating to the Prize can be obtained.

\section{Laboratory Animals Bureau : Congress in Liverpool}

THE annual congress of the Laboratory Animals Bureau will be held this year at the University of Liverpool during April 9-10 and will be opened by Sir Henry Cohen, professor of medicine in the University. During the morning of the first day, papers will be read by a number of technicians, and on the second morning a paper by Dr. J. W. Howie, of the Rowett Research Institute; Prof. R. E. Glover, professor of veterinary pathology in the University of Liverpool, will be in the chair. Admission to these sessions of the congress will be confined to invited technicians only. The afternoons will be devoted to visits to local laboratories and animal houses. Over the two days, a trade exhibition will be held at which animal house furnishings, equipment, feeding stuffs, books, 